This is the peer reviewed version of the following article:Riggs, P. J. (2017), The Perceptions and Experience of the "Passage" of Time. The Philosophical Forum, 48: 3-30. doi:10.1111/phil.12143, which has been published in final form at http://doi.org/10.1111/phil.12143 This article may be used for non-commercial purposes in accordance with Wiley Terms and Conditions for Self-Archiving. https://authorservices.wiley.com/authorresources/Journal-Authors/licensing-open-access/open-access/self-archiving.html (Publisher journal website 12/9/2017)

\title{
THE PERCEPTIONS AND EXPERIENCE OF THE "PASSAGE" OF TIME
}

\author{
PETER J. RIGGS
}

(Published in: The Philosophical Forum 48 (2017): 3-30)

\section{Time and 'Passage'}

It has become very popular over the centuries to speak of time as 'passing' (or 'flowing') in much the same fashion that one might portray a stream of water. Such statements express the notion that time, as we experience it, appears to have a 'dynamic' nature. The 'dynamic' concept of time has become entrenched in modern thought and language for every healthy, conscious human being is aware of the (apparent) 'passage' of time. ${ }^{1}$ This temporal 'passage' goes under several names in the academic literature. Frequently used synonyms for the 'passage' of time include the 'flow'/ 'advance' / 'march' / 'flux' / 'transience' of time and also temporal 'becoming'. These names are not surprising as descriptions of the seemingly 'dynamic' aspect of time are heavily laden with motion metaphors and the use of these metaphors is somewhat unavoidable.

We shall restrict our attention to the two competing realist views of time: the Dynamic View and the Block View. The Dynamic View (also known as the A-Theory of time) holds that the 'passage' of time and the present moment are objective features of the universe. There are different versions of the Dynamic View including: Tensed time; Presentism; and the Growing Block. ${ }^{2}$ All these versions have a common theme based on the very intense, conscious impression of temporal 'passage'. The alternative is the Block

\footnotetext{
${ }^{1}$ Gale (1968), p.7; Lucas (1973), p.8; Schlesinger (1982), pp.515-516; Schuster (1986), p.695; Craig (2000), p.159; Prosser (2007), p.75; Yehezkel (2013), pp.67-68; Muller \& Nobre (2014), p.60; Zakay (2016), p.53.

2 Detailed discussions of the versions of the Dynamic View and temporal 'passage' may be found in: Fine (2005); Dainton (2010a); Dainton (2011a); Price (2011); and Prosser (2016).
} 
View, also known as: the B-Theory of time; Static time; and Eternalism. The most obvious dissimilarity from the Dynamic View is that there is no objective 'passage' of time in the Block View. Much of the discussion over the last decade or so between those who advocate the Dynamic View and those who do not has centred around tenses, tensed facts, and meaning loss between tensed and tenseless propositions. ${ }^{3}$ These arguments regarding tense will not be addressed here. Instead, a novel explanation of the experience of the 'passage' of time within the Block View will be put forward and related ideas explored.

The essence of the 'passage' of time is one of the most central issues of the study of time. ${ }^{4}$ There is little doubt that this is due to the universal feeling of temporal 'passage' as Simon Prosser informs us:

Without the 'sensation of temporal motion' it is hard to see how anyone would come to believe that time passed or even to understand what is meant by the 'passage of time'. ${ }^{5}$

In spite of the feeling, the Dynamic View has been disputed over and over again from both a logical standpoint and that of physics. The Special Theory of Relativity, in particular, offers a powerful resource which shows that there is no unique moment of time to divide the past from the future and that the simultaneity of events is dependent on one's frame of reference. In the absence of a definite divide between past and future that is frame independent, there cannot be an objective, universe-wide 'passage' of time

\footnotetext{
${ }^{3}$ Examples include: Zimmerman (2005); Riggs (2007); Farkas (2008); Beer (2010); and Dyke (2013).

${ }^{4}$ Schlesinger (1980), p.23; Oaklander (1984), pp.1-2; Price (1996), p.12; Yehezkel (2013), p.67; Forbes (2015), p.187.

5 Prosser (2007), p.77.
} 
which all observers will agree on. ${ }^{6}$ Further, the laws of physics themselves do not posit an objective 'present', ${ }^{7}$ which is indispensible to the Dynamic View. There are also quite a number of robust logical objections to the 'passage' of time. ${ }^{8}$ It is not the intention to survey these but merely to acknowledge that such arguments exist in the literature and accept their combined effectiveness with those from physics in disarming arguments that support temporal 'passage'.

Nonetheless, it is the case that the 'passage' of time is taken by most of the population to be an aspect of reality known from everyday experience. ${ }^{9}$ However, on the basis of both logical objections and arguments from physics, a majority of philosophers and physicists have concluded that the 'passage' of time is purely subjective. ${ }^{10}$ Indeed, many argue that temporal 'passage' is an illusion and some even refer to it as a myth. ${ }^{11}$ The situation of divergent attitudes towards the 'passage' of time was once expressed by Paul Fitzgerald (with explicit reference to temporal 'becoming' rather than to 'passage') in the following terms:

Some writers argue that ... temporal becoming is intrinsically mental ... Others hold that temporal becoming characterizes the physical world independently of consciousness ... denials of the reality of temporal becoming leave its defenders gasping

\footnotetext{
${ }^{6}$ The reader is referred to the arguments in: Mozersky (2000); Sider (2001); Saunders (2002); Falk (2003); Greene (2004); Petkov (2006); Peterson \& Silberstein (2010); Wüthrich (2013); Tegmark (2014); Dorato (2015); and Romero (2015).

${ }^{7}$ Greene (2004), p.131.

${ }^{8}$ Criticisms may be found in: Smart (1949); Williams (1951); Smart (1968); Park (1971); Oaklander (1984); Seddon (1987); Horwich (1987); Faye (1989); Price (1996); Oaklander (2002); Tomberlin (2003); Dainton (2011a); Price (2011); Smith (2011); Skow (2011); Yehezkel (2013); Bardon (2013); Leininger (2015); Frischhut (2015); Stefanov (2016); Prosser (2016); and Dieks (2016).

${ }^{9}$ Dainton (2010a), p.28; Rickles \& Kon (2014), p.1; Frischhut (2015), p.143.

10 See: Williams (1951); Smart (1968); Park (1971); Rucker (1977); Penrose (1979); Mellor (1981); Kroes (1985); Nerlich (1994); Mellor (1998); Price (1996); Falk (2003); Greene (2004); Zeh (2007); Prosser (2007); and Prosser (2013a).
} 
... [they] regard it as ... a direct deliverance of experience.

One man's fact is another man's theory. ${ }^{12}$

What is delivered by our human experiences of time shall be considered next.

\section{Temporal Experiences}

The conscious impression that there appears to be temporal 'passage' is, of course, not seriously disputed. We all share the experience of the (apparent) 'passage' of time but the experience itself does not necessitate that such 'passage' objectively exists. Further, as we all know, the (apparent) 'passage' of time does not constitute the sum total of our temporal experiences. The conscious human mind perceives a number of temporal experiences in addition to 'passage', including:

- 'the present';

- durations (i.e. intervals) of time;

- the order of events in time; and

- traces (including memories) of past but not future events.

A basic definition of 'perception' is that it constitutes the processes by which we become aware of objects and events through the body's sensory organs. We shall take a wider meaning of 'perception' than is usually accepted, a meaning that encompasses the range of our temporal experiences. ${ }^{13}$

It will be important to begin with the acknowledgement that our temporal perceptions are different from our spatial perceptions. This is (in part) because we cannot see temporal intervals in our field of vision but we can see the extent of spatial intervals

\footnotetext{
${ }^{11}$ Specific examples include: Williams (1951), p.460; Park (1971), p.20; and Nerlich (1994), pp.233-234.

12 Fitzgerald (1985), p.145 (italics added).

${ }^{13}$ Cf. Le Poidevin (on-line); Zakay (2016), p.55.
} 
and we can both see and (tactually) feel the shape and size of objects in space. ${ }^{14}$ The difference is most pronounced in respect to our awareness of the (apparent) 'passage' of time. This is manifested within the human brain for there are no bodily sensory receptors for time similar to the body's sensory systems for space and sound, ${ }^{15}$ as conveyed in the following statement by the neuropsychologists Ivry and Spencer:

Unlike vision and audition, there are no dedicated sensors for time. Yet the passage of time is as perceptually salient as the color of an apple or the timbre of a tuba. ${ }^{16}$

Nor does there appear to be any centralised, neurobiological clock in the brain, ${ }^{17}$ which might otherwise provide a key, internal timekeeping function to supply a basis for the awareness of 'passage'.

What's more, having the experience of the 'passage' of time occurs when the human mind is in a conscious state, i.e. we are not aware of 'passage' when deeply asleep or unconscious. In the absence of clues such as noises (e.g. alarm clocks) or changing light conditions, people awake not knowing exactly the duration of their sleep/unconscious period and not having had the awareness of the 'passage' of time. ${ }^{18}$ Even in dreams, 'passage' is only simulated as dream content may include remembered and/or imagined events which seem to span time periods far in excess of the duration of sleep. (Note that we will not need to make an essential distinction between mind and brain.)

\footnotetext{
14 Denbign (1981), pp.16-17; Nerlich (1998), p.130; Le Poidevin (2007), pp.98 \& 120; Wittmann (2009), p.1955; van Wassenhove (2009), p.1815.

15 Johnston \& Nishida (2001), p.R427; van der Meer et al. (2006), p.73; Ivry \& Schlerf (2008), p.273; Wittmann (2009), p.1955; Wittmann \& van Wassenhove (2009), p.1809; Merchant et al. (2013), p.314; Muller \& Nobre (2014), p.60.

16 Ivry \& Spencer (2004), p.225.

17 Nobre et al. (2007), p.467; Wittmann \& van Wassenhove (2009), p.1809; Zakay (2016), p.55.
} 
In respect to our perceptions of events, it is the case that we perceive events that have already occurred due to the finite speeds of light, sound, etc. This, of course, tends not to matter in daily life as one's local environment hardly changes during the time interval between the occurrences of events and their perceptions. ${ }^{19}$ However, our awareness of both duration and time order substantially depends on the existence of memories for, without memory, we cannot place most events in their temporal order nor judge the extent of most temporal intervals. ${ }^{20}$ It will not be necessary in what follows to endorse a particular theory of memory. All that is required for our purposes is that memory be a physiological 'recording system' that (in healthy human beings) accumulates information, allows the recall of events, experiences, etc., and allows these to be placed in their temporal order. The standard explanation of why we perceive events successively is that sensory perception and memory formation are causal mechanisms governed by physical processes which produce effects at later times, i.e. these mechanisms operate asymmetrically in time. ${ }^{21}$ The standard explanation is accepted for current purposes as its discussion would take us too far afield.

We shall now consider the first of the above listed temporal experiences because 'the present' is regularly tied to temporal 'passage' in discourse about time. In particular, two questions will be briefly addressed in the remainder of this section:

What constitutes 'the present' in our minds?

Does 'the present' play a crucial role in being aware of temporal 'passage'?

\footnotetext{
18 Meerloo (1968), p.247; Izard (1991), p.60; MacDuffie \& Mashour (2010), p.189.

19 Butterfield (1988), pp.62-64.

20 van der Meer et al. (2006), p.73; Wittmann (2011), pp.2-6; Dieks (2016), p.15.

${ }^{21}$ Mackie (1974), p.160; Horwich (1987), p.129; Faye (1989), p.226; Price \& Weslake (2010), p.414;

Le Poidevin (2015a), p.467.
} 
Much has been written about the (so-called) 'experienced present', i.e. the notion that what we experience as 'the present' is not a durationless instant but rather a short time interval. Although the details of the 'experienced present' continue to be argued about, the available evidence is strongly in favour of the idea being essentially correct. ${ }^{22}$ Cognitive science and neurophysiology have enlightened us about why the 'experienced present' is a time interval in terms of the different response timings of various sensory stimuli, neural processing periods, and the finite speeds of light, sound, and nerve impulses. $^{23}$

Obviously, 'the present' has a special status for human beings - we think of it as being a privileged moment, but why? The special status of 'the present' is bestowed by human beings only being aware of a unique 'experienced present' at any particular time and subsequently, the awareness of more and more 'experienced presents' but only one at a time in a serial order. However, if we were aware of previous 'experienced presents' (as distinct from merely remembering the events which comprised them), or indeed future ones, then what we call 'the present' would lose the special status that it holds for human beings. We would all have a very different perspective towards time. What connects one 'experienced present' to the next is, of course, memory. Incoming information from the external sensory organs is pieced together in our brains and placed in the short-term memory so that we are then ready to handle the next load of incoming data. $^{24}$ We also have (longer term) memories of the series of ordered, previous 'experienced presents'. Each successive 'experienced present' in the series is linked by

\footnotetext{
22 Treisman (1999), p.221; Lestienne (2001), pp.148-150; Binder (2003), pp.47-48; Le Poidevin (2007), pp.79-81; Gallagher (2011), pp.424-425; Ismael (2011), pp.464-465; Le Poidevin (2011), pp.460-461; Wittmann (2011), pp.2-6; Lestienne (2013), p.229; Montemayor (2013), p.121; Dieks (2016), p.15.

${ }^{23}$ Dorato \& Wittmann (2015), p.202.

${ }^{24}$ Le Poidevin (on-line); Falk (2003), p.225.
} 
memory and thereby to broad durations of time which can be recalled. Memory is necessary in providing the mental connection between 'experienced presents' and therefore the 'threads' of our individual temporal reality.

Given the causal nature of our sensory perceptions and that the 'experienced present' is a time interval (rather than a durationless instant), the 'experienced present' for any particular observer is marked out by the observer's brain internally coordinating a set of sensory perceptions. A simple example of such coordination is when one embraces a flower by feeling its petals, smelling its perfume, and observing its colour and texture. These various sensory inputs (which have different speeds of transmission) are coordinated by the brain into a single, present experience of what constitutes a flower. More exactly, when information about occurrences is registered and processed by a conscious observer over the required (neural processing) time interval then 'the present' is delineated in the observer's mind, i.e. a specific 'experienced present' is perceived. ${ }^{25}$ The production of a single, coordinated set of sensory perceptions of which an individual is aware constitutes the 'living in the present' aspect of our existence. Since most causal inputs are from one's immediate spatiotemporal surroundings, the 'experienced present' is predominantly constructed from a set of sensory perceptions of these surroundings. The same causal influences generate similar sets of sensory perceptions in other individuals in the same spatiotemporal region, thereby creating a shared 'present'. ${ }^{26}$

The careful reader would have noticed that the above description of the creation of a specific 'experienced present' in the human mind does not, in itself, include temporal 'passage'. On this basis, what should now be evident (and is of some consequence) is that

\footnotetext{
25 Aaronson (1971), p.373; Zeh (2007), pp.13-14; Callender (2008), pp.349-350; Wittmann (2014), pp.512-513.

${ }^{26}$ Cf. Dorato \& Wittmann (2015), pp.200-202; Wittmann (2016), pp.109-110.
} 
the 'passage' of time does not feature explicitly in the generation of an individual 'experienced present'! (This also tallies with a conclusion by Eva Cassirer that temporal 'passage' is logically independent of 'the present'. ${ }^{27}$ ) Advocates of the Dynamic View might protest but no matter as this is consistent with the Block View. The awareness of the 'passage' of time would appear to be different (albeit related) from that of the 'experienced present'. During our waking/conscious moments then, we seem to be separately aware of both the 'passage' of time and being in 'the present'. Since the 'experienced present' can be differentiated from the experience of the 'passage' of time, we need not further consider the issue of 'the present' and instead, we will concentrate on accounting for the experience of 'passage' ${ }^{28}$

\section{The Perceptions of 'Passage'}

Notwithstanding the compelling arguments that the 'passage' of time is not objective, the experience of 'passage' stubbornly remains and exerts a potent influence on our attitudes to physical reality. The human experience of 'passage' is certainly real even if time is not intrinsically 'dynamic'. Advocates of the Dynamic View hold that the experience of 'passage' justifies their ontological position, i.e. they believe that the experience is veridical. Based on the arguments already cited, one may readily conclude that their error lies in holding this belief. Nevertheless, it is not enough to highlight the deficiencies of the Dynamic View in order to justify the Block View, for the latter's chief shortcoming

\footnotetext{
27 Cassirer (1971), p.5.

28 The reader is referred to accounts of 'the present' in: Butterfield (1988); Le Poidevin (2007); Callender (2008); and Dorato \& Wittmann (2015).
} 
has been its inability to give a truly satisfying narrative of why we seem to experience the 'passage' of time. ${ }^{29}$

It is the case that some advocates of the Block View have attempted to explain the experience of the 'passage' of time as an end result of accumulating memories and being able to ruminate over them. ${ }^{30}$ Simon Prosser has shown that this is inadequate, ${ }^{31}$ as well summarised by Brogaard and Gatzia:

... this [memory] explanation seems implausible for two reasons. The first is that time perception does not seem to require reflection on the contents of our memories. The second is that while the accumulation of memories may explain our sense that time has a direction and that there is an asymmetry between the past and the future, it does not by itself explain why time perceptually seems to pass. ${ }^{32}$

On the other hand, there are commentators who have claimed that the experience of 'passage' is exclusively the experience of change. ${ }^{33}$ Although the experience of change is generally accepted as being part of the experience of the 'passage' of time, perceiving change is unlikely to be the complete picture for existing accounts of change are compatible with change within the Block View, as again observed by Prosser. ${ }^{34}$ Furthermore, restricting the experience of 'passage' to only the experience of change

\footnotetext{
${ }^{29}$ Lucas (1989), p.8; Stuckey et al. (2005), p.219; Diekemper (2007), p.429; van Inwagen (2009), p.81; Paul (2010), p.338; Dainton (2011a), p.385 (fn3); Brogaard \& Gatzia (2015), p.257.

${ }^{30}$ Examples include: Rucker (1977), p.60; Parr (1997), p.52; Mellor (1998), pp.122-123; and Hoerl (2014b), pp.94-95.

31 Prosser (2007), p.96; Prosser (2016), chap.6.

32 Brogaard \& Gatzia (2015), p.258 (italics in original).

33 See, for example: Paul (2010), pp.344-345.

34 Prosser (2012), p.95.
} 
would rule out other possible factors for what is a complex, conscious experience. In this regard, Kenneth Denbign has highlighted that change does not give the whole picture:

We know about 'time' ... from various changes and motions

$\ldots$ and secondly and more directly, from inner experience. ${ }^{35}$

We shall investigate below what might constitute this "inner experience".

Recent attempts to explain the experience of the 'passage' of time within the Block View have made some progress. ${ }^{36}$ Yet, a sufficient description of the experience of 'passage' is still lacking for these recent attempts do not supply a physically adequate origin for the experience. A better answer within the Block View to the question of why we have this experience (and how it originates) is required. In order to seek such an answer, the approach to be pursued here will not assume that the experience of the 'passage' of time is exclusively restricted to the experience of change, to the accumulation of memories, or purely to phenomenological input from the body's sensory organs. ${ }^{37}$ The first step in our analysis will be to suitably characterize the experience of the 'passage' of time and subsequently see what may be drawn from the resulting characterisation. This line of attack will allow the experience of 'passage' to be accounted for within the (spacetime variant of) the Block View and will also have other explanatory benefits. If more than one phenomenon can be explained by this approach, it will add credibility to the resulting theory.

Since the experience of the 'passage' of time is internal to the human mind and is separate from the 'experienced present', a characterisation of the experience of

\footnotetext{
35 Denbign (1981), p.153 (italics added).

36 Recent examples include: Le Poidevin (2007); Paul (2010); Skow (2011); Prosser (2012); Deng (2013a); Leininger (2014); Mozersky (2015); Le Poidevin (2015b); Stefanov (2016); and Prosser (2016). For some critiques, see: Deng (2013b); Hoerl (2014a, 2014b); Brogaard \& Gatzia (2015); Stefanov (2016); and Prosser (2016).
} 
'passage' may be achieved if it is subjected to deliberate and detailed introspection. ${ }^{38}$ This sort of examination (of "inner experience") is not what most philosophers are familiar with performing. Nevertheless, careful introspection can reveal some essential aspects of the experience of 'passage'. The aspect that should surface from initial introspection is (what has been referred to as) our 'basic sense of temporality', which has been depicted by Nathaniel Lawrence as follows:

Below all our refined and reflective concepts of time there is a basic sense of temporality, something felt rather than thought. It pervades experience and is usually no more attended to than is the background hum of machinery in the basement ... 39

If we concentrate on this 'basic sense of temporality' then what emerges from further introspection is the realisation that human beings distinguish the 'passage' of time in two distinctly different ways. The first is perceived immediately whilst the second is not. (Interestingly, such a division also seems to have been 'flagged' as a possibility by J.D. Mabbott as long ago as 1951.40)

The first way that we distinguish the 'passage' of time is the compelling, internal awareness that we all have in our conscious lives that time appears to be 'passing'. This will be called the Primary Perception of 'Passage'. The Primary Perception is the ongoing mental impression, common to all (sane) human beings that time seems to 'pass' unceasingly. It is what we feel as a relentless and irresistible temporal 'motion', ${ }^{41}$ even

\footnotetext{
37 Cf. Evans (2004), chap.1.

38 Wackermann (2005), p.191.

39 Lawrence (1986), p.23 (italics added).

40 Mabbott (1951), p.153.

${ }^{41}$ Lucas (1973), p.13; Rucker (1977), p.60; Schlesinger (1980), p.31; Smart (1980), p.3; Horwich (1987), p.4; Penrose (1989), p.391; Oaklander (1994), p.289; Greene (2004), p.129; Prosser (2007), p.75; van Inwagen (2009), p.80; Price (2011), p.276; Weinert (2013), p.54; Wittmann (2014), p.507.
} 
though it may defy rigorous definition. Note, however, that the Primary Perception is not a judgement of duration, ${ }^{42}$ nor of time order. Dynamic View advocates acknowledge this perception of 'passage' but they, of course, assume that this perception confirms the 'passage' of time as an objective phenomenon. ${ }^{43}$

If we leave aside the issue of the origin of the Primary Perception of 'Passage' for the moment, then its characteristics are identifiable given additional focused introspection (although it is likely that these may not be conspicuous to everyone). The characteristics are as follows:

(i) immediacy;

(ii) constancy in our conscious mental states;

(iii) independence from external sensory stimuli; and

(iv) not dependent on memory.

Characteristics (i), (ii) and (iii) have been separately and individually identified by various commentators on various occasions. ${ }^{44}$ Characteristics (iii), for example, was described in the 1920 s by the British astrophysicist Arthur Eddington. He wrote:

[W]e have direct experience of the time-relations that we ourselves are traversing - a knowledge of time not coming through external sense-organs, but taking a short cut into our consciousness. ${ }^{45}$

\footnotetext{
42 Droit-Volet \& Wearden (2016).

${ }^{43}$ Examples include: Schuster (1986), p.695; Taylor (1997), p.81; and Craig (2000), p.154.

${ }^{44}$ Examples for characteristic (i) include: Williams (1951), p.466; Reichenbach (1958), p.110; Lehmann (1967), p.798; Lawrence (1975), p.198; Penrose (1994), p.384; Schlesinger (1994), p.63; and Dainton (2000), p.124. Examples for characteristic (ii) include: Ornstein (1969), p.15; Rama Rao (1978), p.17; Schlesinger (1982), p.515; and Pauri (1997), p.267. Examples for characteristic (iii) include: Eddington (1929), p.91; and Denbign (1981), p.17.

${ }^{45}$ Eddington (1929), p.51 (italics added).
} 
Characteristic (iii) finds corroborative evidence in the results of sensory deprivation experiments which indicate that the human awareness of the 'passage' of time continues in the absence of external stimuli, although the estimation of experienced time intervals fails to be accurate under such conditions. ${ }^{46}$ Indeed, the (immediate) awareness of 'passage' also seems to continue regardless of one's bodily metabolic status e.g. (medically) induced slow heartbeat rate, as long as the person remains conscious.

Characteristic (iv) is to be expected given that the Primary Perception is immediate and has a constancy. This characteristic is also consistent with the acknowledgement that the accumulation of memories does not account for time always seeming to pass. Further, if the Primary Perception is not dependent on memory then it would still continue in some form with people suffering extreme memory loss and there are indications in favour of this. ${ }^{47}$

The existence of the Primary Perception should be accepted since characteristics (i), (ii) and (iii) have been previously acknowledged and evidence exists in support of characteristics (iii) and (iv). Since the perception of two (or more) events as being successive in time is not the same as perceiving time to be 'passing', 48 tests on judgements of time order are not relevant to the issue of whether the Primary Perception is independent of the accumulation of memories.

The second way that we distinguish the 'passage' of time is not immediate. It will be referred to as the Secondary Perception of 'Passage' and results from the acquired awareness of both time order and duration. This is a different mode of 'perceiving' the

\footnotetext{
46 See, for example: Kenna (1962), p.1007; Ruff et al. (1965), pp.88-89; Aschoff (1985), p.42; Miro et al. (2003), p.148; and Marchetti (2009), p.10.

${ }^{47}$ Lehmann (1967), p.805; Smart (1980), p.13; Horwich (1987), p.35; Smart (1989), p.39; Soulsby (2006), p.88; Dainton (2011b), p.131.

48 Hoerl (2013).
} 
'passage' of time for 'passage' here consists in being aware of having 'lived through' an interval of time rather than 'feeling' that there is temporal 'motion'. Consequently, the Secondary Perception depends on the normal functioning of memory. In other words, this second way appears to our minds as the 'getting from' the beginning to the end of a temporal interval. We all realize (rather obviously) that we have endured a period of time at the end of the period. After attending a meeting, for example, one is consciously aware of having existed from the start to the finish of the meeting, remembering the events comprising the meeting, and of appearing to have 'passed through' its time interval. Clearly, a 'perception' of this kind can only occur later than the relevant time period. The Secondary Perception of 'Passage' counts as a temporal 'perception' for it provides our minds with the data needed for establishing the precedence of most events. This second way contributes significantly to the experience of 'passage'.

The Secondary Perception has also been previously identified (although not by this designation) and recognised as providing a contribution to the experience of 'passage', as summed up by Stuckey, Silberstein and Cifone:

At each moment of conscious awareness I have memories of previous moments from a few seconds back to many years back. This contributes significantly to the illusion that time passes, ... and it helps explain why I have the belief that time is really dynamically unfolding. ${ }^{49}$

It is important to emphasise again that the Secondary Perception (as expressed as an end result of gaining memories) by itself does not explain the experience of the 'passage' of

${ }^{49}$ Stuckey et al. (2005), p.223 (italics added). 
time and therefore there must be more to the experience of 'passage' than just gaining new memories. ${ }^{50}$

What about the (so-called) 'rate' of the 'passage' of time? This is also in need of explanation. Again, we all think that there is such a 'rate' which is commonly expressed by the question - how fast is time 'passing'? The conscious judgement that the 'passage' of time advances at a particular 'rate' is derivative from the awareness of both time order and duration. This can be seen as follows. When a time interval is consciously acknowledged by an individual, it is the period of time after the occurrence of an event that holds some significance to that individual, say the start of a football match. After a period of time into the match, the individual becomes consciously aware of the time interval since the match began. The person then thinks something like 'that time passed quickly (or slowly)', i.e. a judgement is made that time appeared to 'pass' at a certain 'rate' during the time interval which is consciously remembered and referenced to a specific event. Therefore, we do not have continuous awareness of the 'rate' of the 'passage' of time. We are only aware of the 'rate' in hindsight, even when the time interval is as short as a few seconds. Since the 'rate' of 'passage' depends on the awareness of duration and time order, it must be related to the Secondary Perception only which shows why we are aware of the 'rate' in hindsight.

The perceived 'rate' of the 'passage' of time cannot be objective for a number of reasons. First, given the immediacy of the Primary Perception of 'Passage', the perceived 'rate' of 'passage' ought to be immediate also but we judge the 'rate' retrospectively. Second, other people witnessing the same events and at the same location can (and regularly do) judge the 'rate' to be different with the variation depending on, for example,

50 Denbign (1981), p.17; Le Poidevin (2007), p.76; Dainton (2010b), p.57; Prosser (2012), p.96. 
the factors of age, mood, and activity being undertaken. ${ }^{51}$ Third, there are both logical and physical arguments in the literature which show that ascribing a 'rate' to the 'passage' of time is incoherent or, at least, severely problematic. We shall acknowledge these arguments and their effectiveness without surveying them but refer the reader to the extensive literature on the topic. ${ }^{52}$

The identification of two (conceptually) distinct perceptions of temporal 'passage' indicates that they have different causes. These perceptions together produce the experience of the 'passage' of time in human beings. We shall now proceed to give an account of this experience and to look into the physical origins of both the Primary and Secondary Perceptions.

\section{Accounting for the Experience of the 'Passage' of Time}

Prior to presenting an explanation of the experience of 'passage', it will be necessary to define a few specific terms relating to time. Although these terms are commonly found in the literature, their usage and meanings are not uniform. ${ }^{53}$ We begin by representing time, for the purposes of illustration, by a (Euclidean) straight line. Spatial relations between points on a line are characterised as being, to the left, or, to the right. If we were to swap the meaning of left and right around, the structure would be unchanged, i.e. there is no intrinsic way of distinguishing structurally between right and left. ${ }^{54}$ A line may be described as having two orientations as it extends both to the left and to the right. We call the two orientations of time that are represented by left and right on a straight line, earlier

\footnotetext{
51 Wittmann \& Lehnhoff (2005), pp.922-923; Wittmann (2009), pp.1955-1956.

52 See: Black (1962), p.185; Smart (1963), p.136; Seddon (1987), pp.16-17; Smart (1989), p.34; Price (1996), p.13; Harrison (2002), p.11; Klein (2007), p.206; Price (2011), pp.303-304; Skow (2012), pp.385388; and Prosser (2013b), pp.317-320.

53 Kroes (1985), p.105.
} 
and later respectively. The term, temporal asymmetry, denotes the fact that physical processes occur along one orientation of time. Temporal asymmetry is not an intrinsic structural feature of time, it refers to processes occurring in time but not an asymmetry of time itself. 55

The term, temporal anisotropy, denotes a (possible) feature of time where its two orientations are not equivalent. Temporal anisotropy is a structural difference of time where one orientation is intrinsically discernible over the other. The notion of a 'structural difference' is difficult to pin down and conceivably might refer to several possibilities. ${ }^{56}$ The crucial descriptor here is 'intrinsically discernible' for this indicates that there would be a way to determine temporal orientation on the basis of some characteristic of time. Clearly then, temporal anisotropy is not the same as temporal asymmetry. However, temporal anisotropy is not necessarily what is called the 'direction' of time. The latter term is a source of confusion in the literature for 'direction' is taken to mean the orientation of time in some parts of the literature, temporal anisotropy in others, ${ }^{57}$ and has an even stronger ontological meaning within the Dynamic View. ${ }^{58}$ In order to avoid any confusion, the term - 'direction' of time - will not be further mentioned.

The observable asymmetries in time are referred to (perhaps misleadingly) as 'arrows' of time. ${ }^{59}$ Much has been written in both the physics and the philosophical literatures about these 'arrows'. Our experience of the universe at large indicates that the 'arrows' of time are 'laid out' along the later orientation of time, i.e. the temporal

\footnotetext{
${ }^{54}$ Reichenbach (1956), p.26.

55 Price (1996), p.16.

56 The reader is referred to the detailed discussion in Horwich (1987), chap.3.

57 Price (2011), p.292.

58 See also: Earman (1974).
} 
evolution of physical systems 'progresses' from earlier to later in human experience. Several of these 'arrows' are denoted by classes of physical phenomena. Although there is no general consensus on what constitutes the 'arrows' of time, the following classes of phenomena are regularly claimed to provide them: thermodynamics; electromagnetic radiation; exponential decay; biological evolution; quantum mechanical measurement; and gravitational phenomena. ${ }^{60}$ Two other possible 'arrows' of time are much discussed in the literature. These are the expansion of the universe and the psychological progression of time (i.e. the experienced 'passage' of time). The psychological 'arrow' has always been the most difficult to explain. There is also another 'arrow' - the Weak Nuclear decay of some quantum particles which will be discussed below. It has been well argued elsewhere (and will be tentatively accepted here) that all of these 'arrows' of time, except for the psychological one and the Weak Nuclear decay, arise from the various boundary conditions that apply to the respective phenomena. ${ }^{61}$ Despite the interest in the 'arrows' of time (and much debate), one question that remains unanswered is why the different 'arrows' share the same 'alignment' or, as conventionally expressed, why they 'point the same way'. ${ }^{62}$ An answer to this question will be proposed below.

Since temporally asymmetric processes depend on boundary conditions, we can make an inference about the origin of the Secondary Perception of 'Passage' without further ado. It is uncontroversial that the formation of memories, their retention, and memory recall are due to physio-chemical processes that occur within the brain. It is also uncontroversial that these processes are temporally asymmetric and have a dependency

\footnotetext{
59 Price (1996), p.17; Zeh (2007), p.4.

60 Penrose (1979), pp.582-610; Kroes (1985), pp.139-142; Horwich (1987), pp.4-11; Zeh (2007), pp.5-6; Bertolami \& Lobo (2009), pp.9-10; Vaas (2012), pp.7-8; Wallace (2013), pp.273-276; Callender (on-line). ${ }^{61}$ Smart (1963), p.144; Sklar (1977), pp.372 \& 378; Kroes (1985), pp.144-145; Morris (1985), chapter 8; Horwich (1987), pp.12-13; Price (1996), p.116; Zeh (2007), p.4.
} 
on boundary conditions. Now recall that the Secondary Perception is not immediate and requires the existence of memory. It would then follow that the origin of the Secondary Perception is bound up with the boundary conditions imposed upon the relevant phenomena in the brain.

We have seen that the serious theoretical and logical difficulties associated with taking the 'passage' of time as being objective highlight the need for an explanation of the experience of 'passage' that does not require temporal 'passage' to be real. Yet, the intangible feeling of 'passage' has been left substantially unaccounted for in the Block View. Invoking the increase of thermodynamic entropy (i.e. the quantitative measure of disorder) in physical systems has been, and still is, a very popular strategy to try to explain the experience of the 'passage' of time. ${ }^{63}$ It is an almost effortless option to assert that entropy increasing activities in the human brain generate the experience of 'passage'. This entropic story goes along the following lines. First, human awareness of the 'passage' of time depends on being conscious. Second, consciousness involves physical/chemical processes within the human brain (as can be demonstrated by the application of an anaesthetic drug). Third, physical/chemical processes require changes in entropy. Fourth, later physical states overwhelmingly have higher entropy than earlier states.

The conclusion that is then (loosely) drawn is that those entropy increasing processes in the human brain that are related to consciousness also give rise to the experience that time appears to 'pass'. The physicist Sean Carroll provided a recent sketch of the entropic story when he wrote:

62 Mittelstrass (2001), p.25; Bertolami \& Lobo (2009), p.10; Vaas (2012), p.9; Kiefer (2012), p.19.

${ }^{63}$ Examples include: Grünbaum (1973); Atkins (1986); Hawking (1988); and Carroll (2010). 
$[\mathrm{T}]$ he arrow of time exists ... because the universe is full of irreversible processes: something called entropy, which has a stubborn tendency to increase ... The arrow of time is the reason why time seems to flow [to conscious human beings] ... It's why we evolve and metabolize and eventually die. ${ }^{64}$

Using seemingly innocuous premises, the entropic story gives the prima facie impression that its conclusion follows from these premises. This strategy is made all the more easy as knowledge of the workings of the brain in respect to time is still fairly rudimentary, thus allowing the entropic story to have a certain laxity and a lack of sophistication. Nonetheless, the failure of all attempts to show an objective distinction between time's two orientations in terms of increases in entropy ${ }^{65}$ has doomed this strategy.

In respect to the Primary Perception of 'Passage', it is not explained in terms of boundary conditions on physical processes occurring in a temporal structure that is 'static' (where 'static' indicates that there is no temporal 'passage' and not that there are no changes). Why? Well, because the Primary Perception does not depend on memory and the entropic story fails. What then is missing from the explanation of the experience of the 'passage' of time? We shall adopt the (not unreasonable) position that, although time does not 'pass', the actual experience of 'passage' arises (in part) from some physical aspect of the external world. ${ }^{66}$ In other words, the experience of 'passage' itself will be taken as originating from a real feature of time (or spacetime). Some evidence in support of this position will be set out below. Since an objective 'passage' of time has been ruled out and boundary conditions cannot explain both the Primary Perception and

\footnotetext{
${ }^{64}$ Carroll (2010), pp.2-3 (italics in original).

65 Earman (1974), pp.20-23; Sklar (1977), pp.404-409; Faye (1989), pp.200-212; Penrose (2010), pp.5253; Price (2011), pp.284-285.
} 
all the arrows of time together with their common alignment, the option remaining is an account involving some new type of 'static' structure of time. This 'static' structure would have to be sufficiently rich in content that it could round out the explanation of the experience of 'passage'. What sort of 'static' structure of time would be up to the task? We shall return to this question shortly.

Let's first deal with the 'arrow' of time given by the process of the Weak Nuclear decay. Quantum particles exhibit various symmetries such as electric charge conjugation (denoted as $\mathrm{C}$ ), space inversion (denoted as $\mathrm{P}$ ), and time reversibility (denoted as $\mathrm{T}$ ). The details of the symmetries need not concern us. There are also combinations of these particle symmetries, such as the (combined) CP symmetry. A theorem from quantum field theory called the CPT Theorem requires that if there were to be a violation of $\mathrm{CP}$ symmetry (denoted as $\mathrm{CP}$ violation) then there must also be a violation of the symmetry of time reversibility (denoted as T violation). ${ }^{67}$ The occurrence of $\mathrm{T}$ violation would indicate that the time reversed versions of some physical processes are different (e.g. have unequal probabilities of occurring), thereby providing another 'arrow' of time. The Weak Nuclear decay is relevant here as observations of this process can establish if there is $\mathrm{CP}$ violation. It turns out that experimental findings in relation to the Weak Nuclear decay of the particle called the Kaon, do actually show CP violation although there is no evidence that the combined symmetry of CPT is violated. $\mathrm{CP}$ violation in Kaon decay is a very infrequent phenomenon with a probability of occurrence of about 0.2 percent. ${ }^{68}$ The mathematical physicist Roger Penrose made a pertinent remark in 1979:

\footnotetext{
${ }^{66}$ Cf. Penrose (1989), p.394; Davies (1995), p.275. See also Hoerl (2009).

${ }^{67}$ See the account in Sachs (1987), chapter 9.

${ }^{68}$ Cottingham \& Greenwood (2007), p.181.
} 
Yet the tiny effect of an almost completely hidden timeasymmetry seems genuinely to be present in the $K^{0}$ [i.e. Kaon] -decay. It is hard to believe that Nature is not, so to speak, 'trying to tell us something' [about time] ... ${ }^{69}$

If such opposite processes have measurable probabilities of occurring (as has been shown experimentally) then one might conclude that the two orientations of time can be objectively distinguished, ${ }^{70}$ signifying that time itself is anisotropic. This conclusion of temporal anisotropy (rather than just being another 'arrow' of time) is not universally accepted though, ${ }^{71}$ as the border between physical laws and boundary conditions becomes 'blurred' in quantum field theory. ${ }^{72}$ However, given this blurring, concluding that time is anisotropic still is a valid inference based on both the established existence of $\mathrm{CP}$ violation and on the other evidence cited below. ${ }^{73}$

Now it is the case that the fundamental laws of physics do not have a temporal bias inscribed in their form, i.e. the form being time-reversal invariant. ${ }^{74}$ One might thereby think that the existence of even this small CP violation in Kaon decay would be of great concern, as implied by Penrose's comment. However, the rarity of this phenomenon has allowed the inference of $\mathrm{T}$ violation to be almost completely ignored in debates on the nature of time..$^{75}$ Nevertheless, disquiet remains in respect to this possible violation of the time-reversal invariance. Penrose's comment has an 'air of prophecy' as the situation of ignoring the possibility of $\mathrm{T}$ violation because of the rarity of

\footnotetext{
${ }^{69}$ Penrose (1979), p.583.

70 Landsberg (1982), pp.6-7; Doughty (1990), p.38; Price (1996), p.18; Klein (2005), p.101; Klein (2010), p.217.

${ }^{71}$ Cf. Gołosz (2016).

72 Zeh (2007), p.4.

${ }^{73}$ Morris (1985), p.134; Gardner (2005), p.244; Maudlin (2007), pp.117-118.

74 Horwich (1987), p.45; Greene (2004), pp.144-145.
} 
$\mathrm{CP}$ violation no longer applies. More recently, $\mathrm{T}$ violation has been detected independently of CP violation with quantum particles called B-mesons. ${ }^{76}$ The quality and amount of this evidence is such that the evidence and its implications cannot be disregarded, as in the case of the Kaon data. Indeed, theoretical physicist Joan Vaccaro has stated:

The $[\mathrm{T}]$ violation signifies a fundamental asymmetry between the past and future [i.e. earlier and later] and calls for a major shift in the way we think about time..$^{77}$

This "fundamental asymmetry" referred to by Vaccaro ought to be taken as meaning an anisotropy of time (rather than what we have defined as 'asymmetry') precisely because of its fundamental significance. ${ }^{78}$ The evidence for $\mathrm{T}$ violation would then also provide some empirical support for the position that the experience of 'passage' may derive (in part) from an aspect of the physical world, ${ }^{79}$ i.e. due to an anisotropy of time.

This, in turn, suggests that some kind of temporal anisotropy is the feature needed in the 'static' structure of time to explain the Primary Perception and the alignment of the 'arrows' of time. Further, if the fundamental laws of physics do not have a temporal bias then the structure of time should not be such that physical processes would be nomically necessitated along one temporal orientation. Consider instead a 'static' structure of time which has an anisotropy that only provides a strong tendency for physical processes to develop along one orientation of time. Such an anisotropic structure would be (primarily) a topological trait analogous to the grain found in wood. Physical processes in wood (e.g.

\footnotetext{
75 Earman (2002), p.257.

76 Lees et al. (2012); Bernabéu (2013); Bernabéu \& Martínez-Vidal (2015a; 2015b).

77 Vaccaro (2011), p.1569 (italics added).

78 Schwarzschild (2012); Zeller (2012); SLAC Press Release (19 November 2012).

79 Boi (2014), p.94.
} 
cutting or splitting) naturally go along the grain rather than against it, although opposite processes are still possible. Similarly, the kind of temporal anisotropy being proposed would offer a naturally preferred but not a mandatory course for physical processes to develop with the 'grain' of time, i.e. along one orientation of time. The fact that the $\mathrm{CP}$ violation in Kaon decay is very infrequent actually assists the case for an anisotropic structure in which the 'grain' of time only provides a naturally preferred (as against a mandatory) course for physical phenomena. The reason being is that if the temporal anisotropy only gives a preferred course for processes then their temporal inverses would not be forbidden, only less probable.

How might this naturally preferred aspect be illuminated? Initially, we might suppose that the anisotropic structure would involve a greater propensity for physical processes to occur along one orientation of time. Such a propensity would result in different probabilities for events along one orientation as against the other and would be in harmony with time-reversal invariant laws. In order to agree with observation, the probability of events occurring along the later orientation would have to be substantially higher than the corresponding probability along the earlier orientation. A similar probabilistic conception has previously been outlined by Peter Kroes but only in respect to temporal asymmetry. He wrote:

Suppose that instances of a kind of process A occur relative to both orientations of time ... The probability for the occurrence of instances of A relative to the past [i.e. earlier] orientation of time differs from the probability that the occurrences of the instances of A relative to the future [i.e. later] orientation. Then there is a statistical difference ... and it is possible to 
distinguish unambiguously between the two orientations of time $\ldots{ }^{80}$

What about boundary conditions? How then do they fit into this picture? The temporal evolution of physical systems would have to be determined by both the relevant boundary conditions and the anisotropic structure. The role of boundary conditions would be to constrain processes to develop along one orientation of time. Temporal anisotropy would make it more probable than not that this orientation is the one we call later. Such dual constraints would avoid 'begging the question' in some instances by assuming boundary conditions that are themselves asymmetric. ${ }^{81}$

Relativity Theory requires that intervals of spacetime, i.e. the relativistic fusion of space and time, are invariant in all inertial frames of reference (and not space and time separately). It is, therefore, necessary to involve structural aspects of spacetime in addition to aspects of time. As Steven Savitt has suggested:

Philosophy of time should aim at an integrated picture of the experiencing subject with its felt time in an experienced universe with its spatiotemporal structure. ${ }^{82}$

The explanation of why we seem to experience time 'passing' to be given below will offer the essentials of such an integrated picture.

If a temporal 'grain' does exist then it should also be connected with the formal property of temporal orientability which is a feature of the majority of (realistic) spacetime models. A spacetime model is time orientable if a consistent distinction is possible globally between the two orientations of time. What temporal orientability

\footnotetext{
80 Kroes (1985), p.111.

81 Weinert (2013), p.197.

82 Savitt (2009), p.351 (italics in original).
} 
ensures is that when one orientation of time with respect to an event is taken to be later then the 'forward' and 'backwards' light cones of all events can be consistently distinguished. ${ }^{83}$ The 'forward' and 'backwards' light cones of any observer are regions of spacetime that encompass the sets of (respectively, later/earlier) events that could be causally connected to the observer. Note that this involves an element of conventionality as a choice is made as to what counts as being later. However, it should be expected that the 'grain' of time and temporal orientability would go hand-in-hand as the latter would likely follow from the existence of the former. The existence of a 'grain' in time would remove the need for a conventionality element.

What are we now able to surmise? It may reasonably be inferred from the following:

the time-reversal invariance of fundamental physical laws;

experimental confirmation of time reversibility violation;

$>$ the rarity of CP violation in Kaon decay; and

the temporal orientability of realistic spacetime models

that a 'static' spacetime with a temporal anisotropy of the kind portrayed is a legitimate contender for the physical structure of universe within which the experience of 'passage' may be explained. The type of temporal anisotropy outlined provides a basic explanatory framework. It has already been noted that the 'alignment' of the 'arrows' of time (i.e. different physical phenomena developing along the same orientation of time) is an unexplained empirical fact. Temporal anisotropy affords a structural basis to account for this 'alignment' as physical processes would overwhelmingly tend to proceed with the

${ }^{83}$ Sklar (1977), p.301; Kroes (1985), pp.35-36. 
'grain' of time as manifested in a greater propensity for the occurrence of events along one orientation of time (the one called later).

The Primary Perception of 'Passage' and its characteristics also should have a physical foundation within this framework. The characteristics of the Primary Perception and the inability of thermodynamics to provide an objective distinction between the two orientations of time together suggest that the origin of the Primary Perception lies at some deeper physical level than just from inputs from the body's external senses and/or the brain's electrochemistry. ${ }^{84}$ We ought then to look for the origin of the Primary Perception in the structure of time. A 'static' structure in which one of time's orientations is structurally distinguished (i.e. is anisotropic) would offer this origin if this structure is (somehow) perceived by the human mind. Recall the discussion in Section 2 indicating that human perceptions of time are very different from other human perceptions. Eddington made a conjecture along these lines in the 1920's. He wrote:

[A] kind of one-way texture [i.e. 'grain'] involved fundamentally in the structure of Nature ... The mind is cognisant of this texture (as it is cognisant of other features of the physical world) and apprehends it as the passing on of time $\ldots{ }^{85}$

Although such cognisance would assist in explaining the Primary Perception, the question which must follow is - by what means would the cognisance occur? The answer to this will depend crucially (and unavoidably) on the details of the anisotropic structure. Further discussion appears in Section 5.

\footnotetext{
84 Nerlich (1998), p.130.

85 Eddington (1929), p.90 (italics added).
} 
In light of the foregoing considerations, the following account (consistent with the Block View) is presented to explain the experience of the 'passage' of time. An anisotropic structure of 'static' time with a 'grain' that favours the development of phenomena along one of its orientations (later) results both in the Primary Perception of 'Passage' and the 'alignment' of the 'arrows' of time. This 'alignment' and the boundary conditions on physical processes produce all observable events that exhibit a temporal asymmetry and thereby the Secondary Perception of 'Passage'. The Secondary Perception reinforces the Primary Perception (as "topology isn't enough" 86 ) and provides the (apparent) 'rate' of 'passage'. What we have called the two perceptions of 'passage' together produce what appears as the conscious experience that time is 'passing', even though this does not actually occur. The essential features of the human experience of the 'passage' of time are thereby broadly explained without recourse to any 'dynamic' ontology of time.

It follows that the two perceptions of 'passage' that have been described are not perceptions of any actual 'passage' of time at all but these create the illusion that time passes. As Sean Power has remarked:

If our experience is not what it seems to be then we are misinterpreting what we experience. If we cannot help but seem to experience it this way, then we are under an illusion. ${ }^{87}$

The illusionary aspect of 'passage' should not really be surprising. After all, there are many examples of the brain generating illusions involving time and motion which are

\footnotetext{
86 Forbes (2015), p.194.

87 Power (2009), p.24 (italics in original).
} 
well documented in the physiological and psychological literatures. ${ }^{88}$ Even so, the case is made here that a major component of the experience of 'passage' (i.e. the Primary Perception) has a basis founded in the physical structure of time rather than being a cognitive reaction to inputs from the body's sensory organs.

\section{About Temporal Anisotropy}

The proposal of an anisotropic structure of time of the type postulated in order to help explain the experience of the 'passage' of time is likely to be met with more than a little scepticism. Clearly, there are quite a number of issues which surface from this proposal. Consider the following three pertinent questions:

(1) What are the structural details of temporal anisotropy?

(2) How can temporal anisotropy be investigated? and

(3) How does the conscious mind detect the anisotropic structure of time?

In respect to question (1), recall that the kind of temporal anisotropy postulated provides a tendency for physical phenomena to develop along one orientation of time, analogous to wood grain. What form might the 'grain' in the structure of time take? The best candidate is discrete time for a 'grain' in time is compatible with a discrete character rather than a continuum (as continuum implies smooth whereas 'grain' implies the opposite). Although time is usually considered to be continuous, this is not necessitated as the continuity of time is an axiom. ${ }^{89}$ If we dispense with the continuity axiom, then we can theorize about non-continuous structures, in this instance, one where the microstructure of time is discrete. Time being part of spacetime gives a further reason for

\footnotetext{
88 See, for example: Nijhawan (2002); Arnold \& Wilcock (2007); Eagleman (2008); Wittmann \& van Wassenhove (2009); Power (2009); Marchetti (2009); Gruber \& Block (2013); and Le Poidevin (2015b).

${ }^{89}$ Abramenko (1958), p.104. See also: Jaroszkiewicz (2014), pp.11-14.
} 
accepting time to be discrete (and independent of other considerations). Several well grounded physical arguments support the conclusion that the structure of spacetime is discrete at an extremely small scale. ${ }^{90}$ Time may be taken as discrete within such a spacetime structure. ${ }^{91}$ The minuteness of this scale would explain why the assumption of a continuum in our spacetime theories has proved so successful.

If temporal anisotropy is part of the structure of time then it would occur naturally in the (discrete) 'texture' of time along one orientation. The property of spacetime manifolds of being temporally orientable would then appear in the continuum limit of the (discrete) anisotropy. How would the structural anisotropy in the 'texture' of time be constituted? One suggested possible structure is that time is more granular along one orientation than the other..$^{92}$ The particular concept of temporal anisotropy offered here (i.e. analogous to wood grain) is fairly general in that it is unaided by mathematical modelling. What this concept needs is to be informed by new physics. ${ }^{93}$ A mathematical description of the structural anisotropy in the 'texture' of time will likely have to be sought through the (long anticipated but not yet obtained) theory of quantum gravity which should reveal such micro-aspects of spacetime. ${ }^{94}$

In reply to question (2), it is the case that there is only a relatively small amount of empirical data which indicates the existence of any temporal anisotropy (in contrast to temporal asymmetry). Although we can hypothesise about temporal anisotropy, this is necessarily limited unless more data is forthcoming. Unfortunately, 'robust' data will be difficult to obtain if, as suggested, the anisotropy does not offer a mandatory (i.e.

\footnotetext{
${ }^{90}$ See, for example: Szekeres (1995); Greene (2004), pp.490-491; Penrose (2004), p.958; and Adler (2010).

${ }^{91}$ Smolin (2004), p.72.

92 Price (2011), p.292.

93 Adler (2010), p.931.
} 
nomologically necessary) course for the time development of physical systems. Experimentally, the finding of additional evidence that supports temporal anisotropy could be pursued by:

- empirical tests into the Primary Perception of 'Passage' (this is an area of investigation that is almost totally absent from experimental psychology95);

- more extensive physical probing into relevant particle decays; ${ }^{96}$ and

- detection of radiation from distant cosmic events that might indicate discreteness of spacetime. ${ }^{97}$

In response to question (3), recall that it has been hypothesised that temporal anisotropy gives rise to the Primary Perception of 'Passage' through processes internal to the brain. Such processes would have to be connected with human consciousness since we are only aware of the 'passage' of time when the mind is in a conscious state. In other words, an anisotropic spacetime structure being 'registered' by the brain (and by extension to the conscious mind) would be responsible for the Primary Perception. This is consistent with the discussion in Section 2 of how our temporal perceptions are special. However, due to the (necessarily) minute size of discrete time units, the effect of temporal anisotropy would not likely be perceived directly but by way of other physical effects. Therefore, we should look to see whether physical effects in discrete spacetime differ from those in continuous spacetime. It turns out that mathematical modelling does show that some effects in discrete spacetime are not the same as in the continuum case. ${ }^{98}$ This being so, we might conjecture that if spacetime was actually continuous then the

\footnotetext{
94 Williams (2006), p.38; Rovelli (2009), p.5; Hedrich (2010), p.9.

95 Riggs (2012), pp.1069-1070.

96 See, for example: Bigi \& Sanda (2009), pp.462-463; Yamazaki \& Ulmer (2013); and Gajos (2015).

97 Amelino-Camelia et al. (2014).

${ }^{98}$ See, for example: Valsakumar (2005); Sorkin (2009); Philpott et al. (2009); and Riek (2014).
} 
illusion that time 'passes' would either not exist or be different from what we experience it to be. Unfortunately, a detailed answer to question (3) and the exact mechanism for the Primary Perception cannot be provided until we have:

- an in-depth physical description of the structure of discrete time;

- the identification of neurological effects that occur (directly or indirectly) as a result of the anisotropy of time; and

- the physiological basis of the awareness of time (which is yet to be established ${ }^{99}$ ).

\section{Conclusions}

It has been argued that the experience of the (apparent) 'passage' of time is different from our awareness of 'the present' and that there are two ways by which the 'passage' of time is distinguished by conscious human beings. The Primary Perception of 'Passage' is the immediate and continual mental impression that time is 'passing'. The Secondary Perception of 'Passage' is a delayed impression that is derivative from the awareness of duration and time order. The combination of these 'perceptions' gives rise to the deepseated illusion on the conscious mind that time has a 'dynamic' nature. It has been argued that the Primary Perception of 'Passage' is manifested in the brain due to the existence of an intrinsic structural difference between the two orientations of time, i.e. a temporal anisotropy. This anisotropy, in addition, may be used in explaining:

- the 'alignment' of the arrows of time;

- the temporal orientability of spacetime; and

- the rarity of CP violation in Kaon decay.

99 Eagleman et al. (2005), p.10369; Nobre et al. (2007), p.467; Wittmann \& van Wassenhove (2009), p.1809; Meissner \& Wittmann (2011), p.289; Wittmann (2014), p.508. 
It is also suggested that a discrete form of time may provide the structural foundation for such anisotropy.

\section{References}

Aaronson, B.S. (1971). 'Time, Time Stance, and Existence', Studium Generale 24: 369387. Reprinted in Fraser, J.T., Haber, F.C. and Müller, G.H. (eds), The Study of Time. Berlin: Springer, 1972.

Abramenko, B. (1958). 'On Dimensionality and Continuity of Physical Space and Time', British Journal for the Philosophy of Science 9: 89-109.

Adler, R.J. (2010). 'Six Easy Roads to the Planck Scale', American Journal of Physics 78: $925-932$.

Amelino-Camelia, G., Fiore, F., Guetta, D. and Puccetti, S. (2013). 'Quantum-Spacetime Scenarios and Soft Spectral Lags of the Remarkable GRB130427A', Advances in High Energy Physics 2014 (ID 597384).

Arnold, D.H. and Wilcock, P. (2007). 'Cortical Processing and Perceived Timing', Proceedings of the Royal Society B 274: 2331-2336.

Aschoff, J. (1985). 'On the Perception of Time During Prolonged Temporal Isolation', Human Neurobiology 4: 41-52.

Atkins, P.W. (1986). 'Time and Dispersal: The Second Law' in Flood, R. and Lockwood, M. (eds), The Nature of Time. Oxford: Basil Blackwell.

Bardon, A. (2013). A Brief History of the Philosophy of Time. Oxford: Oxford University Press.

Beer, M. (2010). 'Tense and Truth Conditions', Philosophia 38: 265-269.

Bernabéu, J. (2013). 'Time Reversal Violation for Entangled Neutral Mesons', Journal of Physics: Conference Series 447: 012005.

Bernabéu, J. and Martínez-Vidal, F. (2015a). 'Colloquium: Time-reversal Violation with Quantum-entangled B Mesons', Reviews of Modern Physics 8: 165-182.

Bernabéu, J. and Martínez-Vidal, F. (2015b). 'Time-Reversal Violation', Annual Review of Nuclear and Particle Science 65: 403-427.

Bertolami, O. and Lobo, F.S.N. (2009). 'Time and Causation', NeuroQuantology 7: 115 .

Bigi. I.I. and Sanda, A.I. (2009). CP Violation (2nd edn). Cambridge: Cambridge University Press.

Binder, M. (2003). 'Time and the Problem of Consciousness' in Buccheri, R., Saniga, M. and Stuckey, M. (eds), The Nature of Time: Geometry, Physics and Perception.

Dordrecht: Kluwer Academic.

Black, M. (1962). Models and Metaphors. Ithaca: Cornell University Press. 
Boi, L. (2014). 'Asymmetries, Irreversibility, and Dynamics of Time' in Albeverio, S. and Blanchard, P. (eds), Direction of Time. Cham: Springer.

Brogaard, B. and Gatzia, D.E. (2015). 'Time and Time Perception', Topoi 34: 257-263. Butterfield, J. (1988). 'Seeing the Present' in Le Poidevin, R. (ed.), Questions of Time and Tense. Oxford: Clarendon Press.

Callender, C. (2008). 'The Common Now', Philosophical Issues 18: 339-361.

Callender, C. (on-line). 'Thermodynamic Asymmetry in Time'. The Stanford Encyclopedia of Philosophy (Spring 2011 Edition), Zalta, E.N. (ed.), URL = http://plato.stanford.edu/archives/spr2011/entries/time-thermo/.

Carroll, S.M. (2010). From Eternity to Here: The Quest for the Ultimate Theory of Time. New York: Dutton.

Cassirer, E. (1971). 'On the Reality of Becoming', Studium Generale 24: 1-9. Reprinted in Fraser, J.T., Haber, F.C. and Müller, G.H. (eds), The Study of Time. Berlin: Springer, 1972.

Cottingham, W.N. and Greenwood, D.A. (2007). An Introduction to the Standard Model of Particle Physics (2nd edn). Cambridge: Cambridge University Press.

Craig, W.L. (2000). The Tensed Theory of Time: A Critical Examination. Dordrecht: Kluwer Academic.

Dainton, B. (2000). Stream of Consciousness. London: Routledge and Kegan Paul.

Dainton, B. (2010a). Time and Space (2nd edn). Durham, U.K.: Acumen.

Dainton, B. (2010b). ‘Temporal Consciousness', URL = http://www.illc.uva.nl/ seop/entries/consciousness-temporal/\#Bib

Dainton, B. (2011a). 'Time, Passage, and Immediate Experience' in Callender, C. (ed.), The Oxford Handbook of Philosophy of Time. Oxford: Oxford University Press.

Dainton, B. (2011b). 'Time and Temporal Experience' in Bardon, A. (ed.), The Future of the Philosophy of Time. London: Routledge.

Davies, P. (1995). About Time: Einstein's Unfinished Revolution. New York: Simon and Shuster.

Denbign, K. (1981). Three Concepts of Time. Berlin: Springer.

Deng, N. (2013a). 'Our Experience of Passage on the B-Theory', Erkenntnis 78: 713726.

Deng, N. (2013b). 'On Explaining Why Time Seem to Pass', Southern Journal of Philosophy 51: 367-382.

Diekemper, J. (2007). 'B-Theory, Fixity, and Fatalism', Noûs 41: 429-452.

Dieks, D. (2016). 'Physical Time and Experienced Time' in Dolev, Y. and Roubach, M. (eds), Cosmological and Psychological Time. Cham: Springer.

Dorato, M. (2015). 'Presentism and the Experience of Time', Topoi 34: 265-275.

Dorato, M. and Wittmann, M. (2015). 'The Now and the Passage of Time: From Physics to Psychology', KronoScope: Journal for the Study of Time 15: 191-213. 
Doughty, N.A. (1990). Lagrangian Interaction: An Introduction to Relativistic Symmetry in Electrodynamics and Gravitation. Sydney: Addison-Wesley.

Droit-Volet, S. and Wearden, J.H. (2016). 'Passage of Time Judgments Are Not Duration Judgments: Evidence from a Study Using Experience Sampling Methodology', Frontiers in Psychology 7: 176-183.

Dyke, H. (2013). 'Time and Tense' in Dyke, H. and Bardon, A. (eds), A Companion to the Philosophy of Time. Chichester: Wiley-Blackwell.

Eagleman, D.M. (2008). 'Human Time Perception and its Illusions', Current Opinion in Neurobiology 18: 131-136.

Eagleman, D.M., Tse, P.U., Buonomano, D., Janssen, P., Nobre, A.C. and Holcombe, A.O. (2005). 'Time and the Brain: How Subjective Time Relates to Neural Time', The Journal of Neuroscience 25: 10369-10371.

Earman, J. (1974). 'An Attempt to Add a Little Direction to "The Problem of the Direction of Time" , Philosophy of Science 41: 15-47.

Earman, J. (2002). 'What Time Reversal Invariance Is and Why It Matters', International Studies in the Philosophy of Science 16: 245-264.

Eddington, A.S. (1929). The Nature of the Physical World. Cambridge: Cambridge University Press.

Evans, V. (2004). The Structure of Time: Language, Meaning and Temporal Cognition. Amsterdam: John Benjamins.

Falk, A. (2003). 'Time Plus the Whoosh and Whiz' in Jokíc A. and Smith, Q. (eds), Time, Tense, and Reference. London: MIT Press.

Farkas, K. (2008). 'Time, Tense, Truth', Synthèse 160: 269-284.

Faye, J. (1989). The Reality of the Future: An Essay on Time, Causation and Backward Causation. Odense: Odense University Press.

Fine, K. (2005). 'Tense and Reality' in Modality and Tense: Philosophical Papers. Oxford: Oxford University Press.

Fitzgerald, P. (1985). 'Four Kinds of Temporal Becoming', Philosophical Topics 13: $145-177$.

Forbes, G.A. (2015). ‘Accounting for Experiences as of Passage: Why Topology Isn't Enough', Topoi 34: 187-194.

Frischhut, A.M. (2015). 'What Experience Cannot Teach Us About Time', Topoi 34: $143-155$.

Gajos, A. (2015). 'A Direct Test of T Symmetry in the Neutral K Meson System at KLOE-2', Journal of Physics: Conference Series 631: 012018-1-012018-10.

Gale, R.M. (1968). The Language of Time. London: Routledge \& Kegan Paul.

Gallagher, S. (2011). 'Time in Action' in Callender, C. (ed.), The Oxford Handbook of Philosophy of Time. Oxford: Oxford University Press.

Gardner, M. (2005). The New Ambidextrous Universe: Symmetry and Asymmetry from Mirror Reflections to Superstrings. New York: Dover. 
Gołosz, J. (2016). 'Weak Interactions: Asymmetry of Time or Asymmetry in Time?', Journal for General Philosophy of Science (Online: 01 June 2016).

Greene, B. (2004). The Fabric of the Cosmos: Space, Time and the Texture of Reality. London: Penguin.

Gruber, R.P. and Block, R.A. (2013). 'The Flow of Time as a Perceptual Illusion', The Journal of Mind and Behavior 34: 91-100.

Grünbaum, A. (1973). Philosophical Problems of Space and Time (Boston Studies in the Philosophy of Science Volume 12). Dordrecht: Reidel.

Harrison, E. (2002). 'On the Physical Nature of Time', KronoScope: Journal for the Study of Time 2: 9-19.

Hawking, S.W. (1988). A Brief History of Time. London: Bantam.

Hedrich, R. (2010). 'Quantum Gravity Motivations and Alternatives', Physics and Philosophy 2010 (Id: 016).

Hoerl, C. (2009). 'Time and Tense in Perceptual Experience', Philosophers' Imprint 9 (12): $1-18$.

Hoerl, C. (2013). 'A Succession of Feelings, in and of Itself, is Not a Feeling of Succession', Mind 122: 373-417.

Hoerl, C. (2014a). 'Do We (Seem To) Perceive Passage?', Philosophical Explorations: An International Journal for the Philosophy of Mind and Action 17: 188-202.

Hoerl, C. (2014b). 'Time and the Domain of Consciousness', Annals of the New York Academy of Sciences 1326: 90-96.

Horwich, P. (1987). Asymmetries in Time: Problems in the Philosophy of Science.

Cambridge, Mass.: M.I.T. Press.

Ismael, J. (2011). 'Temporal Experience' in Callender, C. (ed.), The Oxford Handbook of Philosophy of Time. Oxford: Oxford University Press.

Ivry, R.B. and Schlerf, J.E. (2008). 'Dedicated and Intrinsic Models of Time Perception', Trends in Cognitive Sciences 12: 273-280.

Ivry, R.B. and Spencer, R.M.C. (2004). 'The Neural Representation of Time', Current Opinion in Neurobiology 14: 225-232.

Izard, C.E. (1991). The Psychology of Emotion. Berlin: Springer.

Jaroszkiewicz, G. (2014). Principles of Discrete Time Mechanics. Cambridge:

Cambridge University Press.

Johnston, A. and Nishida, S. (2001). 'Time Perception: Brain Time or Event Time?', Current Biology 11: R427-R430.

Kenna, J.C. (1962). 'Sensory Deprivation Phenomena: Critical Review and Explanatory Models', Proceedings of the Royal Society of Medicine 55: 1005-1010.

Kiefer, C. (2012). 'Can the Arrow of Time Be Understood from Quantum Cosmology?' in Mersini-Houghton, L. and Vaas, R. (eds), The Arrows of Time: A Debate in Cosmology. Berlin: Springer. 
Klein, E. (2005). Chronos: How Time Shapes our Universe (trans. by G. Burney). New York: Thunder's Mouth Press.

Klein, E. (2007). 'About the Confusion Between the Course of Time and the Arrow of Time', Foundations of Science 12: 203-221.

Klein, E. (2010). 'What Does the "Arrow of Time” Stand For?', Natural Science 2: 212219.

Kroes, P. (1985). Time: Its Structure and Role in Physical Theories. Dordrecht: Reidel.

Landsberg, P.T. (1982). 'Introduction' in Landsberg, P.T. (ed.), The Enigma of Time. Bristol: Hilger.

Lawrence, N. (1975). 'Temporal Passage and Spatial Metaphor' in Fraser, J.T. and Lawrence, N. (eds), The Study of Time II. Berlin: Springer.

Lawrence, N. (1986). 'The Origins of Time' in Fraser, J.T., Lawrence, N. and Haber, F.C. (eds), Time, Science, and Society in China and the West. The Study of Time V. Amherst, MA.: University of Massachusetts Press.

Lees, J.P. et al. (2012). 'Observation of Time-Reversal Violation in the $B^{0}$ Meson System', Physical Review Letters 109: 211801.

Lehmann, H.E. (1967). 'Time and Psychopathology', Annals of the New York Academy of Sciences 138: 798-821.

Le Poidevin, R. (on-line). 'The Experience and Perception of Time'. The Stanford Encyclopedia of Philosophy (2009 Edition), Edward N. Zalta (ed.), URL = $<$ http://plato.stanford.edu/entries/time-experience/>.

Le Poidevin, R. (2007). The Images of Time: An Essay on Temporal Representation. Oxford: Oxford University Press.

Le Poidevin, R. (2011). 'The Temporal Prison', Analysis 71: 456-465.

Le Poidevin, R. (2015a). 'Perception and Time' in Matthen, M. (ed.), The Oxford Handbook of Philosophy of Perception. Oxford: Oxford University Press.

Le Poidevin. R. (2015b). 'Stopped Clocks, Silent Telephones and Sense Data: Some Problems of Time Perception', Topoi 34: 241-248.

Leininger, L. (2014). 'On Mellor and the Future Direction of Time', Analysis Reviews 74 (1): $148-157$.

Leininger, L. (2015). 'Presentism and the Myth of Passage', Australasian Journal of Philosophy 93: 724-739.

Lestienne, R. (2001). 'The Duration of the Present' in Soulsby. M.P. and Fraser, J.T. (eds), Time: Perspectives at the Millenium. The Study of Time X. Westport: Bergin \& Garvey.

Lestienne, R. (2013). 'On the Limits of Time in the Brain', KronoScope: Journal for the Study of Time 13: 228-239.

Lucas, J.R. (1973). A Treatise on Time and Space. London: Methuen.

Lucas, J.R. (1989). The Future: An Essay on God, Temporality and Truth. Oxford: Basil Blackwell. 
Mabbott, J.D. (1951). 'Our Direct Experience of Time', Mind 60: 153-167. Reprinted in Gale, R.M. (ed.), The Philosophy of Time: A Collection of Essays. London: Macmillan, 1968.

MacDuffie, K. and Mashour, G.A. (2010). 'Dreams and the Temporality of Consciousness', American Journal of Psychology 123: 189-197.

Mackie, J. (1974). The Cement of the Universe: A Study of Causation. Oxford: Clarendon Press.

Maudlin, T. (2007). The Metaphysics Within Physics. Oxford: Oxford University Press.

Merchant, H., Harrington, D.L. and Meck, W.H. (2013). 'Neural Basis of the Perception and Estimation of Time', Annual Review of Neuroscience 36: 313-336.

Marchetti, G. (2009). 'Studies on Time: A Proposal on How to get out of Circularity', Cognitive Processing 10: 7-40.

Mellor, D.H. (1981). Real Time. Cambridge: Cambridge University Press.

Mellor, D.H. (1998). Real Time II. London and New York: Routledge.

Meissner, K. and Wittmann, M. (2011). 'Body Signals, Cardiac Awareness, and the Perception of Time', Biological Psychology 86 (2011): 289-297.

Meerloo, J.A.M. (1968). 'The Time Sense in Psychiatry' in Fraser, J.T. (ed.), The Voices of Time: A Cooperative Survey of Man's Views of Time as Expressed by the Sciences and by the Humanities. London: Allen Lane.

Miro, E., Cano, M.C, Espinosa-Fernandez, L. and Buela-Casal, G. (2003). 'Time Estimation During Prolonged Sleep Deprivation and Its Relation to Activation Measures', Human Factors 45: 148-159.

Mittelstrass, J. (2001). 'On the Philosophy of Time', European Review 9: 19-29.

Montemayor, C. (2013). Minding Time: A Philosophical and Theoretical Approach to the Psychology of Time. Leiden; Boston: Brill.

Morris, R. (1985). Time's Arrows: Scientific Attitudes Towards Time. New York: Touchstone.

Mozersky, M.J. (2000). 'Time, Tense and Special Relativity', International Studies in the Philosophy of Science 14: 221-236.

Mozersky, M.J. (2015). Time, Language, and Ontology: The World from the B-Theoretic Perspective. Oxford: Oxford University Press.

Muller, T. and Nobre, A.C. (2014). 'Perceiving the Passage of Time: Neural Possibilities', Annals of the New York Academy of Sciences 1326: 60-71.

Nerlich, G. (1994). What Spacetime Explains: Metaphysical Essays on Space and Time. Cambridge: Cambridge University Press.

Nerlich, G. (1998). 'Time as Spacetime' in Le Poidevin, R. (ed.), Questions of Time and Tense. Oxford: Clarendon Press.

Nijhawan, R. (2002). 'Neural Delays, Visual Motion and the Flash-lag Effect', Trends in Cognitive Sciences 6: 387-393. 
Nobre, A.C., Correa, A. and Coull, J.T. (2007). 'The Hazards of Time', Current Opinion in Neurobiology 17: 465-470.

Oaklander, L.N. (1984). Temporal Relations and Temporal Becoming. A Defence of a Russellian Theory of Time. Lanham, MD.: University Press of America.

Oaklander, L.N. (1994). 'Introduction. The Problem of Our Experience of Time' in Oaklander, L.N. and Smith, Q. (eds), The New Theory of Time. New Haven: Yale University Press.

Oaklander, L.N. (2002). 'Presentism, Ontology and Temporal Experience' in Callender, C. (ed.), Time, Reality and Experience. Cambridge: Cambridge University Press.

Ornstein, R.E. (1969). On the Experience of Time. Harmondsworth, U.K.: Penguin Books.

Park, D. (1971). 'The Myth of the Passage of Time', Studium Generale 24: 19-30.

Reprinted in Fraser, J.T., Haber, F.C. and Müller, G.H. (eds), The Study of Time. Berlin: Springer, 1972.

Parr, H.C. (1997). Time, Science and Philosophy. Cambridge: Lutterworth Press.

Paul, L.A. (2010). 'Temporal Experience', Journal of Philosophy 107: 333-359.

Reprinted in Bardon, A. (ed.), The Future of the Philosophy of Time. London: Routledge, 2011.

Paul, L.A. (2014). 'Experience and the Arrow' in Wilson, A. (ed.), Chance and Temporal Asymmetry. Oxford: Oxford University Press.

Pauri, M. (1997). 'The Physical Worldview and the Reality of Becoming' in Faye, J., Scheffler, U. and Urchs, M. (eds), Perspectives on Time. Dordrecht: Kluwer Academic.

Penrose, R. (1979). 'Singularities and Time-asymmetry' in Hawking, S.W. and Israel, W. (eds), General Relativity: An Einstein Centenary Edition. Cambridge: Cambridge University Press.

Penrose, R. (1989). The Emperor's New Mind: Concerning Computers, Minds, and the Laws of Physics. London: Vintage Press.

Penrose, R. (1994). Shadows of the Mind: A Search for the Missing Science of Consciousness. Oxford: Oxford University Press.

Penrose, R. (2004). The Road to Reality: A Complete Guide to the Laws of the Universe. London: Jonathon Cape.

Penrose, R. (2010). Cycles of Time: An Extraordinary New View of the Universe. London: Bodley Head.

Peterson, D. and Silberstein, M. (2010). 'Relativity of Simultaneity and Eternalism: In Defense of the Block Universe' in Petkov, V. (ed.), Space, Time, and Spacetime: Physical and Philosophical Implications of Minkowski's Unification of Space and Time. Berlin: Springer.

Petkov, V. (2006). 'Is There an Alternative to the Block Universe View?' in Dieks, D. (ed.), The Ontology of Spacetime. Amsterdam: Elsevier.

Philpott, L., Dowker, F. and Sorkin, R.D. (2009). 'Energy-Momentum Diffusion from Spacetime Discreteness', Physical Review D 79: 124047. 
Power, S.E. (2009). 'A Philosophical Introduction to the Experience of Time', NeuroQuantology 7: 16-29.

Price, H. (1996). Time's Arrow and Archimedes' Point: New Directions for the Physics of Time. Oxford: Oxford University Press.

Price, H. (2011). 'The Flow of Time' in Callender, C. (ed.), The Oxford Handbook of Philosophy of Time. Oxford: Oxford University Press.

Price, H. and Weslake, B. (2010). 'The Time-Asymmetry of Causation' in Beebee, H., Hitchcock, C. and Menzies, P. (eds), The Oxford Handbook of Causation. Oxford: Oxford University Press.

Prosser, S. (2007). 'Could We Experience the Passage of Time?', Ratio 20: 75-90.

Prosser, S. (2012). 'Why Does Time Seem to Pass?', Philosophy and Phenomenological Research 85: 92-116.

Prosser, S. (2013a). 'Passage and Perception', Nô̂s 47: 69-84.

Prosser, S. (2013b). 'The Passage of Time' in Dyke, H. and Bardon, A. (eds), A

Companion to the Philosophy of Time. Chichester: Wiley-Blackwell.

Prosser, S. (2016). Experiencing Time. Oxford: Oxford University Press.

Rama Rao, P. (1978). Studies in Time Perception. Delhi: Concept Publications.

Reichenbach, H. (1956). The Direction of Time (ed. M. Reichenbach). Berkeley and Los Angeles: University of California Press.

Reichenbach, H. (1958). The Philosophy of Space and Time (trans. by M. Reichenbach and J. Freund). New York: Dover.

Riek, R. (2014). 'A Derivation of a Microscopic Entropy and Time Irreversibility from the Discreteness of Time', Entropy 16: 3149-3172.

Rickles, D. and Kon, M. (2014). 'Interdisciplinary Perspectives on the Flow of Time', Annals of the New York Academy of Sciences 1326: 1-8.

Riggs, P.J. (2007). 'Nowness and Loss of Meaning in Tensed Propositions', KronoScope: Journal for the Study of Time 7: 79-83.

Riggs, P.J. (2012). 'What Do We Feel When We 'Feel' Time 'Passing'?', Journal of Consciousness Exploration \& Research 3: 1064-1073.

Romero, G.E. (2015). 'Present Time', Foundations of Science 20: 135-145.

Rovelli, C. (2009). 'Unfinished Revolution' in Oriti, D. (ed.), Approaches to Quantum

Gravity: Toward a New Understanding of Space, Time and Matter. Cambridge:

Cambridge University Press.

Rucker, R.v.B. (1977). Geometry, Relativity and the Fourth Dimension. New York:

Dover.

Ruff, G.E., Levy, E.Z. and Thaler, V.H. (1965). 'Factors Influencing Reactions to Reduced Sensory Input' in Solomon, P. et al., Sensory Deprivation. Cambridge, Mass: Harvard University Press.

Sachs, R.G. (1987). The Physics of Time Reversal. Chicago: Chicago University Press. 
Saunders, S. (2002). 'How Relativity Contradicts Presentism' in Callender, C. (ed.), Time, Reality and Experience. Cambridge: Cambridge University Press.

Savitt, S.F. 2009. 'The Transient nows' in: Myrvold, W.C. and Christian, J. (eds), Quantum Reality, Relativistic Causality, and Closing the Epistemic Circle: Essays in Honour of Abner Shimony. Amsterdam: Springer.

Schlesinger, G.N. (1980). Aspects of Time. Indianapolis: Hackett.

Schlesinger, G.N. (1982). 'How Time Flies', Mind 91: 501-523.

Schlesinger, G.N. (1994). Timely Topics. New York: St. Martin's Press.

Schuster, M.M. (1986). 'Is the Flow of Time Subjective?', Review of Metaphysics 39: 695-714.

Schwarzschild, B.M. (2012). 'Time-reversal asymmetry in particle physics has finally been clearly seen', Physics Today 65 (11): 16-18.

Seddon, K. (1987). Time: A Philosophical Treatment. New York: Croom Helm.

Sider, T. (2001). Four-Dimensionalism: An Ontology of Persistence and Time. Oxford: Clarendon Press.

Sklar, L. (1977). Space, Time and Spacetime. Berkeley and Los Angeles: University of California Press.

Skow, B. (2011). 'Experience and the Passage of Time', Philosophical Perspectives 25: 359-387.

Skow, B. (2012). 'One Second Per Second', Philosophy and Phenomenological Research 85: 377-389.

SLAC National Accelerator Laboratory Press Release (19 November 2012). 'BaBar Experiment Confirms Time Asymmetry'. Available at:

https://www6.slac.stanford.edu/research/accelerators-and-society.aspx

Smart, J.J.C. (1949). 'The River of Time', Mind 58: 483-494. Reprinted in Flew, A. (ed.), Essays in Conceptual Analysis. London: Macmillan, 1963.

Smart, J.J.C. (1963). Philosophy and Scientific Realism. London: Routledge \& Kegan Paul.

Smart, J.J.C. (1968). Between Science and Philosophy. New York: Random House.

Smart, J.J.C. (1980). 'Time and Becoming' in van Inwagen, P. (ed.), Time and Cause: Essays Presented to Richard Taylor. Dordrecht: Reidel.

Smart, J.J.C. (1989). Our Place in the Universe: A Metaphysical Discussion. Oxford: Basil Blackwell.

Smith, N.J.J. (2011). 'Inconsistency in the A-Theory', Philosophical Studies 156: 231247.

Smolin, L. (2004). 'Atoms of Space and Time', Scientific American (January 2004): 6675. Reprinted in Scientific American 23 (Autumn 2014): 94-103. 
Sorkin, R.D. (2009). 'Does Locality Fail at Intermediate Length-Scales?' in Oriti, D. (ed.), Approaches to Quantum Gravity: Toward a New Understanding of Space, Time and Matter. Cambridge: Cambridge University Press.

Soulsby, M.P. (2006). 'Telling the Time of Memory Loss: Narrative and Dementia' in Parker, J.A., Crawford, M. and Harris, P. (eds), Time and Memory. The Study of Time XII. Leiden-Boston: Brill.

Stefanov, A.S. (2016). 'Can the "Illusion" of the Flowing Time be Explained?', The Philosophical Forum 47: 207-221.

Stuckey, M., Silberstein, M. and Cifone, M. (2005). 'Reversing the Arrow of Explanation in the Relational Blockworld: Why Temporal Becoming, the Dynamical Brain and the External World Are All "In The Mind" ' in Buccheri, R., Elitzur, A.C. and Saniga, M. (eds), Endophysics, Time, Quantum and the Subjective. Singapore: World Scientific.

Szekeres, P. (1995). 'Discrete Space-time' in Carey, A.L., Ellis, W.J., Pearce, P.A. and Thomas, A.W. (eds), Confronting the Infinite. Singapore: World Scientific.

Taylor, R. (1997). Metaphysics (4th edn). New York: Prentice-Hall.

Tegmark, M. (2014). Our Mathematical Universe. New York: Knopf.

Tomberlin, J.E. (2003). 'Actualism and Presentism' in Jokić, A. and Smith, Q. (eds), Time, Tense and Reference. Cambridge, MA.: MIT Press.

Treisman, M. (1999). 'The Perception of Time: Philosophical Views and Psychological Evidence' in Butterfield, J. (ed.), The Arguments of Time. Oxford: Oxford University Press.

Vaas, R. (2012). 'Time After Time - Big Bang Cosmology and the Arrows of Time' in Mersini-Houghton, L. and Vaas, R. (eds), The Arrows of Time: A Debate in Cosmology. Berlin: Springer.

Vaccaro, J.A. (2011). 'T Violation and the Unidirectionality of Time', Foundations of Physics 41:1569-1596.

Valsakumar, M.C. (2005). 'Stochasticity, Decoherence and an Arrow of Time from the Discretization of Time?', Pramana - Journal of Physics 64: 593-606.

van der Meer, E., Krüger, F., Strauch, D. and Kuchinke, L. (2006). 'Coding of Temporal Order Information in Semantic Memory' in Parker, J.A., Crawford, M. and Harris, P. (eds), Time and Memory. The Study of Time XII. Leiden-Boston: Brill.

van Inwagen, P. (2009). Metaphysics (3rd edn). Boulder, Co.: Westview Press.

van Wassenhove, V. (2009). 'Minding Time in an Amodal Representational Space', Philosophical Transactions of the Royal Society B 364: 1815-1830.

Wackermann, J. (2005). 'Experience of Time Passage: Phenomenology, Psychophysics, and Biophysical Modelling' in Buccheri, R., Elitzur, A.C. and Saniga, M. (eds), Endophysics, Time, Quantum and the Subjective. Singapore: World Scientific.

Wallace, D. (2013). 'The Arrow of Time in Physics' in Dyke, H. and Bardon, A. (eds), A Companion to the Philosophy of Time. Chichester: Wiley-Blackwell.

Weinert, F. (2013). The March of Time: Evolving Concepts of Time in Light of Scientific Discoveries. Berlin: Springer. 
Williams, D.C. (1951). 'The Myth of Passage', Journal of Philosophy 48: 457-472. Reprinted in Gale, R.M. (ed.), The Philosophy of Time: A Collection of Essays. London: Macmillan, 1968.

Williams, R.M. (2006). 'Discrete Quantum Gravity', Journal of Physics: Conference Series 33: 38-48.

Wittmann, M. (2009). 'The Inner Experience of Time', Philosophical Transactions of the Royal Society B 364: 1955-1967.

Wittmann, M. (2011). 'Moments in Time', Frontiers in Integrative Neuroscience 5: 1-9.

Wittmann, M. (2014). 'Embodied Time: The Experience of Time, the Body, and the Self' in Arstila, V. and Lloyd, D. (eds), Subjective Time: the Philosophy, Psychology, and Neuroscience of Temporality. Cambridge, Mass.: MIT Press.

Wittmann, M. (2016). 'The Duration of Presence' in Mölder, B., Arstila, V. and Øhrstrøm, P. (eds), Philosophy and Psychology of Time. Cham: Springer.

Wittmann, M. and Lehnhoff, S. (2005). 'Age Effects in Perception of Time', Psychological Reports 97: 921-935.

Wittmann, M. and van Wassenhove, V. (2009). 'The Experience of Time: Neural Mechanisms and the Interplay of Emotion, Cognition and Embodiment', Philosophical Transactions of the Royal Society B 364: 1809-1813.

Wüthrich, C. (2013). 'The Fate of Presentism in Modern Physics' in Ciunti, R., Miller, K. and Torrengo, G. (eds), New Papers on the Present-Focus on Presentism. Munich: Philosophia Verlag.

Yamazaki, Y. and Ulmer, S. (2013). 'CPT Symmetry Tests with Cold p and Antihydrogen', Annalen der Physik (Berlin) 525: 493-504.

Yehezkel, G. (2013). 'The Illusion of the Experience of the Passage of Time', Disputatio V: $67-80$.

Zeh, H.D. (2007). The Physical Basis of the Direction of Time. Berlin: Springer.

Zakay, D. (2016). 'Psychological Time' in Mölder, B., Arstila, V. and Øhrstrøm, P. (eds), Philosophy and Psychology of Time. Cham: Springer.

Zeller, M. (2012). 'Particle Decays Point to an Arrow of Time', Physics 5: 129-131.

Zimmerman, D.W. (2005). 'The A-Theory of Time, The B-Theory of Time, and "Taking Tense Seriously" , Dialectica 59: 401-457. 